\title{
Propriedades emulsificantes e estabilidade do biossurfactante produzido por Bacillus subtilis em manipueira
}

\author{
Studies of emulsifying properties and stability of the biosurfactant produced by Bacillus subtilis in cassava wastewater
}

Francisco Fábio Cavalcante BARROS ${ }^{1 \star}$, Cedenir Pereira de QUADROS ${ }^{1}$, Gláucia Maria PASTORE${ }^{1}$

\begin{abstract}
Resumo
Devido ao elevado poder tensoativo, baixa toxidez e biodegradabilidade, os lipopeptídios produzidos por bactérias do gênero Bacillus estão entre os biossurfactantes mais conhecidos e estudados. Estes compostos são apontados como potenciais insumos para diversos setores industriais, inclusive o de alimentos. Para que seja possível sua aplicação industrial, no entanto, é necessário que estes compostos apresentem estabilidade e manutenção de suas propriedades em condições extremas, que estão freqüentemente associadas a esses processos. O objetivo deste trabalho foi estudar a estabilidade do biossurfactante produzido pela linhagem LB5a de Bacillus subtilis, cultivado em manipueira (resíduo da industrialização da mandioca) em um processo piloto. Os estudos de estabilidade foram realizados em função da variação de temperatura, $\mathrm{pH}$ e concentração salina. Foram realizadas avaliações da sua capacidade emulsificante em misturas de água com hidrocarbonetos e óleos vegetais, bem como a estabilidade das emulsões formadas. Os resultados mostraram que o biossurfactante foi estável à temperatura de $100{ }^{\circ} \mathrm{C}$ por 140 minutos e a $121^{\circ} \mathrm{C}$ por até 60 minutos, à concentração de 2,5 a $20 \%$ de $\mathrm{NaCl}$ e na faixa de pH de 6 a 10 . Em relação ao índice de emulsão com 24 horas $\left(\mathrm{IE}_{24}\right.$ ), o biossurfactante mostrou elevados valores para diversos hidrocarbonetos cíclicos e alifáticos, além de óleos vegetais com diferentes perfis de ácidos graxos. Todos os resultados obtidos demonstraram a importância do biossurfactante para potenciais aplicações em diversos ramos industriais.

Palavras-chave: biossurfactante; manipueira; Bacillus subtilis; índice de emulsificação.
\end{abstract}

\begin{abstract}
Due to the high surface activity, low toxicity, and biodegradability lipopeptides produced by bacteria of the genus Bacillus are among the best biosurfactants known and studied. These compounds are mentioned as potential inputs for various industrial sectors. However, to allow their implementation in industrial processes, it is necessary stability under extreme conditions often associated with of such processes and the maintenance of their properties. The aim of this work was to study the stability of the biosurfactant produced by Bacillus subtilis strain LB5a grown in cassava wastewater in a pilot process. Stability studies were carried out by varying the temperature, $\mathrm{pH}$, and salt $(\mathrm{NaCl})$ concentration. Another study was the evaluation of their emulsifying index in mixtures of water with hydrocarbons and vegetable oils as well as the stability of the emulsions formed. The results showed that the biosurfactant was stable under all combination of temperature and time tested: $100^{\circ} \mathrm{C}$ for 140 minutes and $121^{\circ} \mathrm{C}$ for up to 60 minutes. It was also stable in concentrations of $\mathrm{NaCl}$ from 2.5 to $20 \%$, and $\mathrm{pH}$ from 6 to 10 . The biosurfactant showed higher values of emulsion index at 24 hours $\left(\mathrm{EI}_{24}\right)$ to various cyclical and aliphatic hydrocarbons when compared with SDS. The vegetable oils emulsions were stable despite the fact that the profiles of fatty acid chain in the oils were different. All results described characterize these compounds as potential emulsifiers for different industrial applications.

Keywords: biosurfactant; cassava wastewater; Bacillus subtilis; emulsification index.
\end{abstract}

\section{Introdução}

Biossurfactantes são compostos com atividade tensoativa, produzidos por várias espécies de microrganismos. Esses compostos compreendem uma grande diversidade de moléculas quimicamente diferentes como glicolipídios, lipossacarídios, fosfolipídios, ácidos graxos e lipídios neutros, lipopeptídios (DESAI; DESAI, 1993; BOGNOLO, 1999; LANG, 2002; MAIER, 2003) e alguns polímeros (DESAI; DESAI, 1993; MAIER, 2003).

Na medida em que possuem alta atividade tensoativa, os biossurfactantes apresentam importantes propriedades, como detergência, emulsificação, lubrificação, capacidade espumante, capacidade molhante, solubilização e dispersão de fases
(KOSARIC, 1992; DESAI; DESAI, 1993; BANAT, 2000). Diversos setores demandam compostos com estas características, tais como: petróleo, petroquímico, alimentos, bebidas, cosméticos, farmacêutico, mineração, metalúrgico, agroquímico, fertilizantes, ambiental, papel e celulose, entre outros (KOSARIC, 1992; DESAI; BANAT, 1997; BANAT, 2000; BANAT; MAKKAR; CAMEOTRA, 2000; MULLIGAN, 2005). Entre os biossurfactantes mais efetivos estão os lipopeptídios produzidos por bactérias do gênero Bacillus, especialmente os produzidos pelo Bacillus subtilis (BOGNOLO, 1999).

A grande maioria dos surfactantes disponíveis comercialmente é produzida a partir de derivados de petróleo. É

${ }^{1}$ Universidade Estadual de Campinas - UNICAMP, Rua Monteiro lobato, 80, Cidade Universitária “Zeferino Vaz”, Campinas - SP, Brasil, E-mail: fabiobarros10@gmail.com

${ }^{*}$ A quem a correspondência deve ser enviada 
patente, entretanto, o aumento da preocupação ambiental, o que leva à procura de biossurfactantes como alternativa aos produtos existentes. Além disso, outras propriedades destes biocompostos, como baixa toxidez, biodegradabilidade e propriedades biológicas, os colocam como alternativas promissoras (KOSARIC, 1992; DESAI; BANAT, 1997; HOLMBERG, 2001; MAIER, 2003; CAMEOTRA; MAKKAR, 2004; BARROS et al., 2007).

Processos industriais e ambientais estão freqüentemente associados a condições extremas de temperatura, pressão, força iônica, $\mathrm{pH}$ e presença de solventes orgânicos (CAMEOTRA; MAKKAR, 1998). Diversos estudos têm avaliado a estabilidade dos biossurfactantes frente a essas condições. Isto ocorre em função da necessidade de uma avaliação do comportamento destes compostos para que sua utilização seja viabilizada (CAMEOTRA; MAKKAR, 1998; MAKKAR; CAMEOTRA, 1999; COSTA, 2005; BARROS, 2007; BARROS et al., 2007). Estudos prévios têm demonstrado haver significativa estabilidade dos biossurfactantes mesmo quando comparados a compostos sintéticos bastante utilizados pela indústria (KIM et al., 1997; NITSCHKE; PASTORE, 2006; BARROS et al., 2007).

O objetivo deste trabalho consiste no estudo da estabilidade do biossurfactante frente a condições extremas e, como desdobramento, verificar a estabilidade da emulsão de óleos e hidrocarbonetos em água, usando compostos tensoativos produzidos por uma linhagem de Bacillus subtilis em manipueira, um resíduo agroindustrial da indústria de fécula e farinha de mandioca, em escala piloto.

\section{Material e métodos}

\subsection{Produção do biossurfactante}

O biossurfactante foi produzido por Bacillus subtilis linhagem LB5a, pertencente à coleção do Laboratório de Bioaromas (DCA/FEA/Unicamp) (NITSCHKE; FERRAZ; PASTORE, 2004). Foi realizada fermentação em fermentador piloto com capacidade para 80 L Pilot New Brunswick 8000 MP 80 (New Brunswick Scientific, Edison, NJ, EUA), utilizando-se manipueira pré-tratada, segundo Barros et al. (2008), como substrato.

As condições de processo foram $35^{\circ} \mathrm{C}, 20 \mathrm{~L} /$ hora de aeração e agitação de $150 \mathrm{rpm}$. A recuperação primária do surfactante foi realizada por meio da coleta da espuma produzida no interior do fermentador, conforme descrito por Kim et al. (1997), Davis, Lynch e Varley (2001), Barros et al. (2008) e Costa (2005). Em seguida ao colapso da espuma, a biomassa foi removida por centrifugação, o sobrenadante foi acidificado com solução $2 \mathrm{M}$ de $\mathrm{HCl}$ para pH 2,0 e a biomassa, novamente centrifugada. Após a centrifugação, o sobrenadante foi descartado e o precipitado foi suspenso em água. $\mathrm{O} \mathrm{pH}$ foi elevado para 7,0 com solução $1 \mathrm{M}$ de $\mathrm{NaOH}$ e o precipitado, seco em estufa a $50{ }^{\circ} \mathrm{C}$. Após secagem do produto, foi feita extração com clorofórmio/metanol (65:15) e novamente seco em estufa (MAKKAR; CAMEOTRA, 1997; COSTA, 2005). O produto obtido foi identificado como biossurfactante semipurificado e utilizado nos experimentos posteriores.

\subsection{Estudo do poder tensoativo}

Foram medidas a tensão superficial (TS), a diluição micelar crítica $1 / 10\left(\mathrm{CMD}^{-1}\right)$ e $1 / 100\left(\mathrm{CMD}^{-2}\right)$ (MAKKAR; CAMEOTRA, 1997; COSTA, 2005) e a Concentração Micelar Crítica (CMC) (SHEPPARD; MULLIGAN, 1987) de uma solução aquosa de $1 \mathrm{mg} \cdot \mathrm{mL}^{-1}$ do biossurfactante semipurificado.

\subsection{Estudo de estabilidade térmica}

Uma solução aquosa de $1 \mathrm{mg} \cdot \mathrm{mL}^{-1}$ do biossurfactante foi colocada em uma série de tubos de ensaio de $15 \mathrm{~mm}$ de diâmetro e submetidos a $100^{\circ} \mathrm{C}$ por períodos de $20,40,60,100$ e 140 minutos. Outra amostra da mesma solução também foi aquecida, mas a $121^{\circ} \mathrm{C}$ e por períodos de 20, 40 e 60 minutos. Após tratamento térmico, cada solução foi resfriada até temperatura ambiente para medição da TS, $\mathrm{CMD}^{-1}$ e CMD ${ }^{-2}$ (MAKKAR; CAMEOTRA, 1997; COSTA, 2005). Os tratamentos foram realizados em triplicata e as medições de tensão superficial foram realizadas em uma média de cinco medidas.

\subsection{Estudo de estabilidade frente ao $\mathrm{pH}$}

Uma solução aquosa de $1 \mathrm{mg} \cdot \mathrm{mL}^{-1}$ do biossurfactante semipurificado teve seu $\mathrm{pH}$ ajustado para valores de 2, 4, 6, 8, 12 e 13, por meio de adição de $\mathrm{HCl} 1$ e $0,1 \mathrm{~N}$ ou $\mathrm{NaOH} 1$ e $0,1 \mathrm{~N}$. Após 30 minutos em banho-maria à temperatura de $25 \pm 1^{\circ} \mathrm{C}$, a TS, a CMD ${ }^{-1}$ e CMD $^{-2}$ foram medidas. Os tratamentos foram realizados em triplicata e as medições de tensão superficial em uma média de cinco medidas.

\subsection{Estudo de estabilidade frente à força iônica}

A partir de uma solução estoque do biossurfactante semipurificado com concentração de $10 \mathrm{mg} . \mathrm{mL}^{-1}$, foram preparadas duas séries de soluções de forma que em uma série a concentração final de biossurfactante ficasse em $1 \mathrm{mg} \cdot \mathrm{mL}^{-1} \mathrm{e}$, na outra, em $2,5 \mathrm{mg} \cdot \mathrm{mL}^{-1}$. Cada uma das séries também foi preparada de forma que a concentração salina $(\mathrm{NaCl})$ final ficasse em 2,5; ; 10 e $20 \%$. Após 30 minutos em banho-maria à temperatura de $25 \pm 1^{\circ} \mathrm{C}$, foram medidas a TS, a $\mathrm{CMD}^{-1}$ e a $\mathrm{CMD}^{-2}$. Os tratamentos foram realizados em triplicata e as medições de tensão superficial em uma média de cinco medidas.

\subsection{Estudo da atividade emulsificante}

Uma solução de biossurfactante de $1 \mathrm{mg} \cdot \mathrm{mL}^{-1}$ foi misturada em tubos de ensaio com tampa rosqueável a compostos hidrofóbicos na proporção de 4:6 e homogeneizados em agitador de tubos, em velocidade máxima, por 2 minutos. Os tubos foram deixados em repouso à temperatura de $25^{\circ} \mathrm{C}$. Durante 96 horas, em intervalos regulares de 24 horas contadas a partir do momento da homogeneização, foram efetuadas medidas da altura da Camada Emulsificada (CE) e da Altura Total (AT) dos líquidos no tubo. $\mathrm{O}$ índice de emulsificação foi obtido através da fórmula: $\mathrm{IE}(\%)=(\mathrm{CE} / \mathrm{AT})^{\star} 100$, descrita por Cooper e Goldenberg (1987). 
Os compostos utilizados foram divididos em dois grupos. O primeiro grupo foi composto dos seguintes hidrocarbonetos: pentano, hexano, octano, decano, benzeno, tolueno, gasolina e diesel. O segundo, com óleos vegetais: algodão (Gossypium hirsutum), babaçu (Attalea speciosa), canola (Brassica napus), gergelim (Sesamum indicum), girassol (Helianthus annus), milho (Zea mays) e soja (Glycine max). Paralelamente, foram preparadas duas soluções de outros emulsificantes: uma de dodecil sulfato de sódio (SDS) e a outra de lecitina de soja, na mesma concentração de $1 \mathrm{mg} \cdot \mathrm{mL}^{-1}$ do biossurfactante. Os tratamentos foram realizados em duplicata.

\section{Resultados e discussão}

\subsection{Atividade superficial}

Os resultados mostraram que o biossurfactante testado exibiu uma excelente atividade tensoativa, reduzindo a tensão da água de 72,31 para 27,01 mN/m. Estes resultados confirmam os dados reportados por Cooper et al. (1981), Peypoux, Bonmartin e Wallach (1999) e Nitschke e Pastore (2006). Os valores de $\mathrm{CMD}^{-1}$ e $\mathrm{CMD}^{-2}$ foram, respectivamente, 30,12 e $35,48 \mathrm{mN} / \mathrm{m}$. Estes valores mostram-se próximos aos encontrados por Sheppard e Mulligan (1987), mas são um pouco maiores que os reportados por Nitschke e Pastore (2006), que foram de 28 e $32 \mathrm{mN} / \mathrm{m}$, respectivamente.

A concentração micelar crítica encontrada foi de $12 \mathrm{mg} . \mathrm{L}^{-1}$. O valor é bastante próximo ao encontrado por Cos-

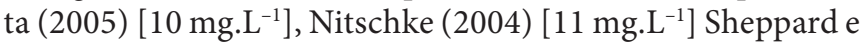
Mulligan (1987) [14 mg. $\left.\mathrm{L}^{-1}\right]$ e Deleu et al. (1999) [10 mg. $\left.\mathrm{L}^{-1}\right]$ e menor que os encontrados por Kim et al. (1997) [40 mg. $\left.\mathrm{L}^{-1}\right]$ e Cooper et al. (1981) [25 mg. $\mathrm{L}^{-1}$ ]. O valor de concentração micelar crítica encontrado caracteriza este biossurfactante como um poderoso agente tensoativo, por formar micelas na concentração de $12 \mathrm{mg} \cdot \mathrm{mL}^{-1}$. As diferenças entre os diversos valores apresentados em diferentes trabalhos justificam-se, provavelmente, causadas pelas diferentes composições do meio, condições de cultivo e linhagens produtoras.

A partir de todos os dados relacionados, é possível afirmar que o biossurfactante produzido pela linhagem LB5a apresenta grande atividade superficial (tensoativo) e CMC baixa, propriedades estas o que o caracterizam como um bom tensoativo (BOGNOLO, 1999).

\subsection{Estudos de estabilidade}

Conforme apontado, os biossurfactantes apresentam propriedades que os caracterizam como potenciais insumos em processos industriais. Na medida em que estes processos estão, freqüentemente, associados a condições extremas, faz-se necessária uma avaliação da estabilidade desses biossurfactantes.

Diversos experimentos têm demonstrado que os biossurfactantes produzidos por bactérias do gênero Bacillus são estáveis em diversas condições. O biossurfactante produzido pela cepa de Bacillus subtilis C9, por exemplo, apresentou amplo limite de estabilidade e manutenção de propriedades emulsificantes em temperaturas de 20 a $100{ }^{\circ} \mathrm{C}$ por 1 hora, $\mathrm{pH}$ de 5,0 a 9,5 e concentrações salinas de $1.000 \mathrm{mM}$ de $\mathrm{NaCl}$ e $10 \mathrm{mM}$ de $\mathrm{CaCl}_{2}$ (KIM et al., 1997). Costa (2005), utilizando outra linhagem, produziu surfactante com estabilidade a variações de temperatura de $100{ }^{\circ} \mathrm{C}$ por 2 horas, $121^{\circ} \mathrm{C}$ por 0,5 hora e $135^{\circ} \mathrm{C}$ por 1 hora, $\mathrm{pH}$ de 6 a 12, concentração salina $(\mathrm{NaCl})$ de $15 \%$ e presença das enzimas proteolíticas bromelina, ficina, papaína e tripsina, além de boas propriedades emulsificantes de óleos vegetais e hidrocarbonetos.

A estabilidade do biossurfactante foi avaliada frente a variações de temperatura, $\mathrm{pH}$ e força iônica. Quando são avaliados os efeitos do tratamento térmico em diversos intervalos de tempo e temperaturas, é possível observar que não houve mudança significativa na atividade superficial do biossurfactante (Figuras 1 e 2).

Os valores de $\mathrm{TS}, \mathrm{CMD}^{-1}$ e $\mathrm{CMD}^{-2}$ não tiveram variação significativa ao longo do tempo quando foi avaliado o tratamen-

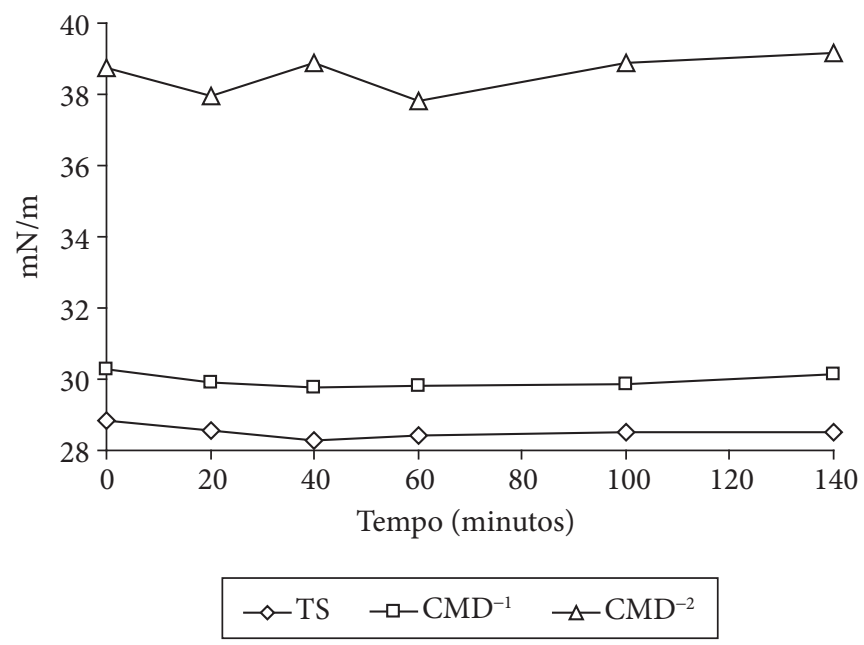

Figura 1. TS, $\mathrm{CMD}^{-1}$ e $\mathrm{CMD}^{-2}$ do biossurfactante submetido a tratamento térmico a $100^{\circ} \mathrm{C}$.

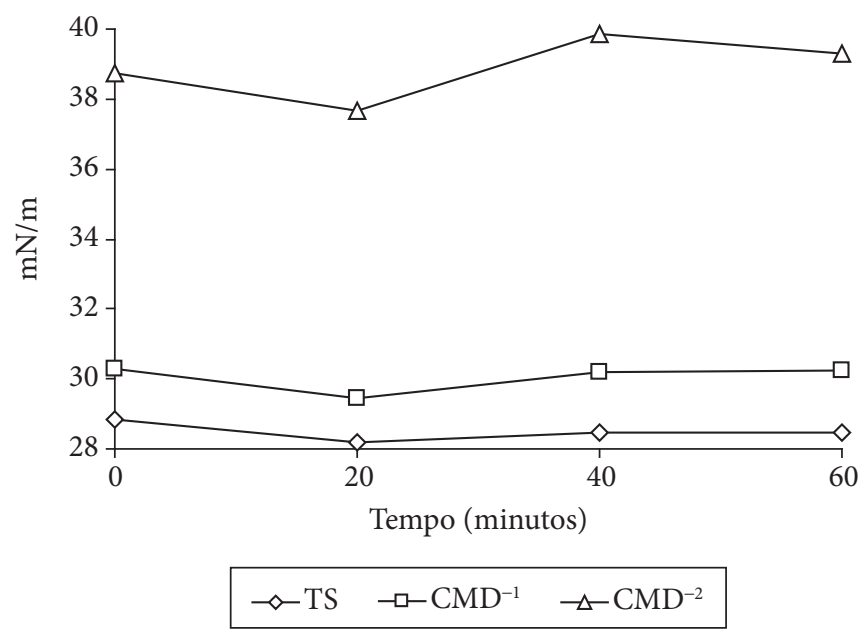

Figura 2. TS, $\mathrm{CMD}^{-1}$ e $\mathrm{CMD}^{-2}$ do biossurfactante submetido a tratamento térmico a $121^{\circ} \mathrm{C}$. 
to a $100{ }^{\circ} \mathrm{C}$, apesar de ter apresentado uma pequena oscilação nos valores de $\mathrm{CMD}^{-2}$, não sendo observada nenhuma tendência clara. Estas flutuações estão, provavelmente, associadas a variações experimentais. No entanto, é possível observar que os valores nos dois últimos tratamentos, de 100 e 140 minutos, são justamente os dois maiores valores de $\mathrm{CMD}^{-2}$. No caso do tratamento a $121^{\circ} \mathrm{C}$, houve uma pequena variação, partindo de valores próximos a $38 \mathrm{mN} / \mathrm{m}$ nos primeiros 20 minutos para valores próximos a $39,5 \mathrm{mN} / \mathrm{m}$ a partir de 40 minutos.

Quando testado frente à força iônica (Figura 3), o biossurfactante mostrou estabilidade em todas as concentrações salinas pesquisadas. Quando são comparadas as duas séries de concentração de biossurfactante com concentrações de 1 e $2,5 \mathrm{mg} \cdot \mathrm{mL}^{-1}$, somente são observadas diferenças nas medidas de $\mathrm{CMD}^{-2}$. Neste caso, a concentração do surfactante está próxima ou abaixo da CMC, o que faz com que qualquer alteração de concentração afete de forma significativa a tensão superficial. Quando são comparados os valores de TS e $\mathrm{CMD}^{-1}$, os valores obtidos são bastante próximos, pois como o surfactante apresenta uma concentração acima da CMC, não há significativa elevação na tensão mesmo que haja redução de sua concentração na solução.

A Figura 4 mostra os resultados obtidos quando foram estudados os efeitos de alterações de $\mathrm{pH}$ sobre a atividade superficial. Quando foram comparados os valores de TS frente à variação do $\mathrm{pH}$, observou-se que os menores valores, 27,5 e $28,5 \mathrm{mN} / \mathrm{m}$, correspondem aos $\mathrm{pH} 6$ e 8 , respectivamente, ou seja, próximos à neutralidade. Houve uma brusca

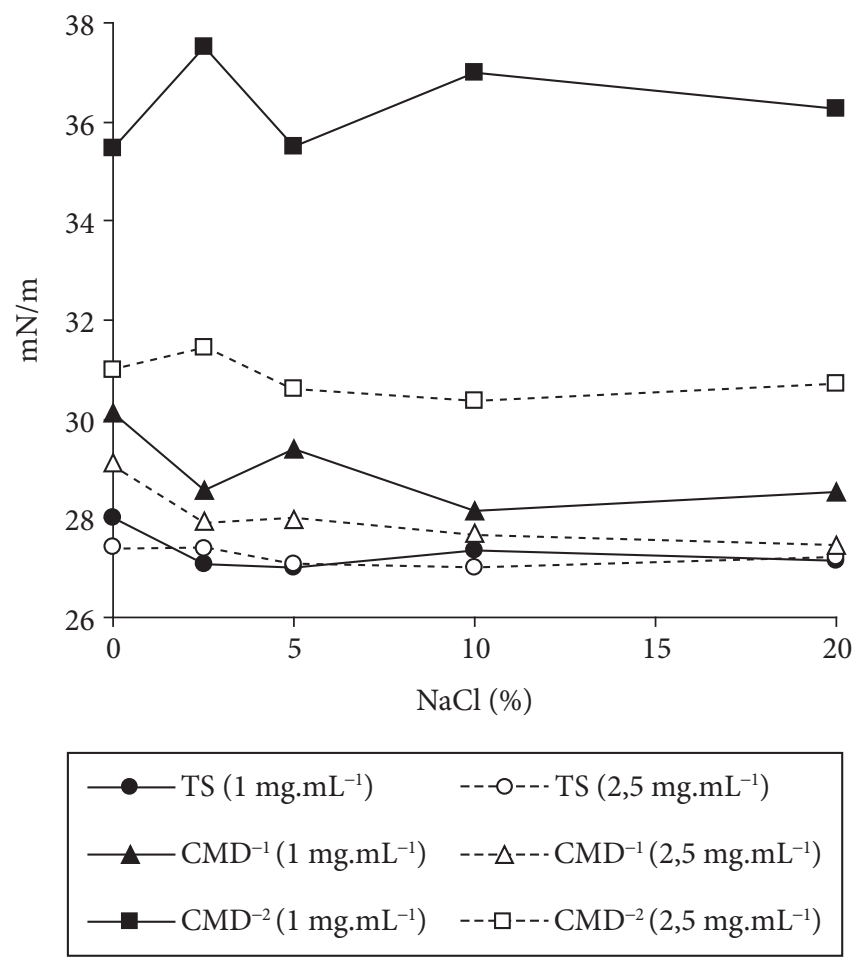

Figura 3. Efeito da força iônica sobre a atividade superficial de diferentes concentrações de biossurfactante. elevação na TS quando o pH foi reduzido de 6 para 4 e tal fato se deve, provavelmente, à precipitação do biossurfactante. Fenômeno semelhante foi descrito por Kim et al. (1997) e Costa (2005). Acima de pH 6, houve um gradual aumento nos valores de tensão até pH 12, quando a TS atingiu valor de $30,8 \mathrm{mN} / \mathrm{m}$. Entre pH 12 e 13, o valor da tensão aumenta de forma mais vigorosa. $\mathrm{A} \mathrm{CMD}^{-1}$ teve um comportamento muito semelhante à TS, provavelmente devido à concentração do surfactante na solução ainda estar próxima à concentração micelar crítica (CMC).

$\mathrm{Na}$ avaliação do comportamento da $\mathrm{CMD}^{-2}$ frente ao $\mathrm{pH}$, foram observadas algumas diferenças em relação aos perfis da TS e da $\mathrm{CMD}^{-1}$.

As mudanças nos valores de TS foram bem mais acentuadas, com evidente elevação entre os valores de pH 2 e 4 e uma elevação entre os pHs 8 e 10. Quanto aos valores de $\mathrm{CMD}^{-2}$, o fato de a concentração do biossurfactante estar abaixo da CMC implica que para qualquer redução da concentração - em função de precipitação, por exemplo - haverá um grande impacto na variação da tensão superficial. Por este motivo, as diferenças entre os valores de tensão superficial foram evidentemente maiores, fato que não ocorre nas outras diluições. $\mathrm{O}$ mesmo fenômeno acontece nas soluções alcalinizadas.

Quando neutralizadas novamente, tanto as amostras de $\mathrm{pH}$ ácido como as de $\mathrm{pH}$ alcalino mostram uma redução da TS para níveis semelhantes aos encontrados antes da acidificação ou da alcalinização. Este fenômeno mostra que há apenas uma precipitação e, com a neutralização da amostra, o biossurfactante volta a ficar solúvel e reduz-se, deste modo, a tensão superficial.

Cooper et al. (1981) relataram que a acidificação da solução contendo biossurfactante de Bacillus subtilis para pH 2 eleva a tensão superficial para $62 \mathrm{mN} / \mathrm{m}$. O fato de o valor de tensão superficial voltar a $27 \mathrm{mN} / \mathrm{m}$ com a neutralização, em $\mathrm{pH}$ igual a 6, mostra a dependência das propriedades surfactantes da surfactina em relação ao pH. Este comportamento se deve ao fato de que, em meio ácido, a surfactina precipita sem, contudo, ter sua estrutura

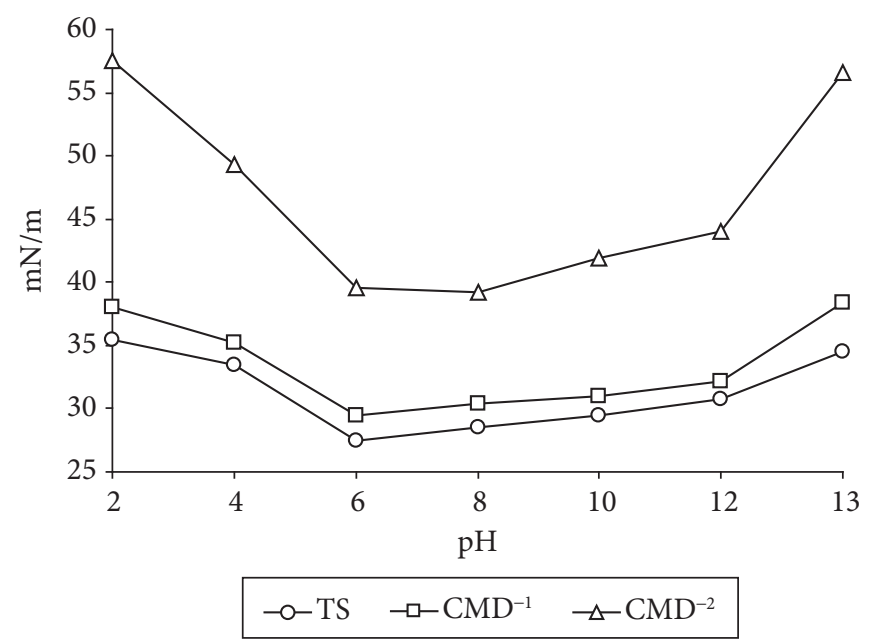

Figura 4. TS, $\mathrm{CMD}^{-1}$ e $\mathrm{CMD}^{-2}$ em função do $\mathrm{pH}$. 
alterada (COOPER et al., 1981; COSTA, 2005). Esta característica representa uma vantagem adicional do biossurfactante avaliado, pois mesmo quando submetido a condições mais extremas de $\mathrm{pH}$, há manutenção da sua estrutura química original.

\section{3 Índice de emulsificação e da estabilidade da emulsão}

Um importante parâmetro de avaliação do poder de um emulsificante é o Índice de Emulsificação (IE) e da estabilidade da emulsão (COOPER; GOLDENBERG, 1987; ABU-RUWAIDA et al., 1991; NITSCHKE, 2004; COSTA, 2005). Por meio da análise inicial dos hidrocarbonetos (Figura 5), é possível observar que todas as emulsões testadas - exceto o tolueno + biossurfactante (BS) - apresentaram elevados valores de IE. Os valores foram próximos entre os surfactantes testados para todos os hidrocarbonetos no período de 24 horas $\left(\mathrm{IE}_{24}\right)$, embora o dodecil Sulfato de Sódio (SDS) tenha apresentado valores melhores em todos os casos. As maiores diferenças foram com o decano, o tolueno e o diesel, cujas relações $\mathrm{IE}_{24}(\mathrm{BS}) / \mathrm{IE}_{24}(\mathrm{SDS})$ foram, respectivamente, 1,25, 2,52 e 1,24 . Em apenas quatro casos, as emulsões apresentaram uma redução percentual do IE maior que $10 \%$ no período entre 24 e 96 horas: pentano + SDS, com redução de 13,3\%; hexano + SDS, com redução de 20,4\%; diesel + biossurfactante, com redução de $76,4 \%$, e gasolina + SDS, com redução de $87,1 \%$. A diferença entre os comportamentos do diesel e da gasolina poderia sugerir uma maior estabilidade da emulsão formada pelo biossurfactante com hidrocarbonetos de cadeia longa, uma vez que o diesel é composto por uma mistura de hidrocarbonetos de massa molecular mais elevada que a da gasolina. Entretanto, não foi observada nenhuma tendência nesse sentido nos demais hidrocarbonetos analisados.

$\mathrm{Na}$ análise dos resultados referentes à emulsificação de óleos vegetais (Figura 6), observou-se que a efetividade dos surfactantes foi bastante diferente entre os óleos estudados. Além do biossurfactante de Bacillus subtilis LB5a (BS), o dodecil Sulfato de Sódio (SDS) e a lecitina de soja (LEC) foram testados para servirem como referência. Neste estudo, o SDS apresentou resultados melhores ou bastante próximos do $\mathrm{IE}_{24}$ do biossurfactante em todos os óleos analisados. Quando foram comparados os resultados de estabilidade de emulsão, o SDS apresentou os melhores resultados, seguido do BS e da LEC. A exceção foi o óleo de babaçu, no qual o BS apresentou significativa vantagem quando comparado aos outros surfactantes do estudo, no que tange à avaliação da estabilidade da emulsão no período estudado.

Em relação à estabilidade, cinco emulsões apresentaram uma redução percentual do IE maior que $10 \%$ no período analisado entre 24 e 96 horas para o biossurfactante (Figura 6): milho $(26,0)$; oliva $(15,8)$; babaçu $(17,3)$; algodão $(17,6)$, e gergelim $(62,9)$. No entanto, as emulsões foram estáveis nas primeiras horas, com a maior parte da variação ocorrendo depois das 72 horas. A exceção deu-se com o óleo de gergelim, cuja variação ocorreu após 48 horas.

Não houve relação entre o tipo e o tamanho das cadeias carbônicas dos ácidos graxos que compõem os óleos testados (Tabela 1) e os IE24 (Figura 6) das emulsões com biossurfactante.

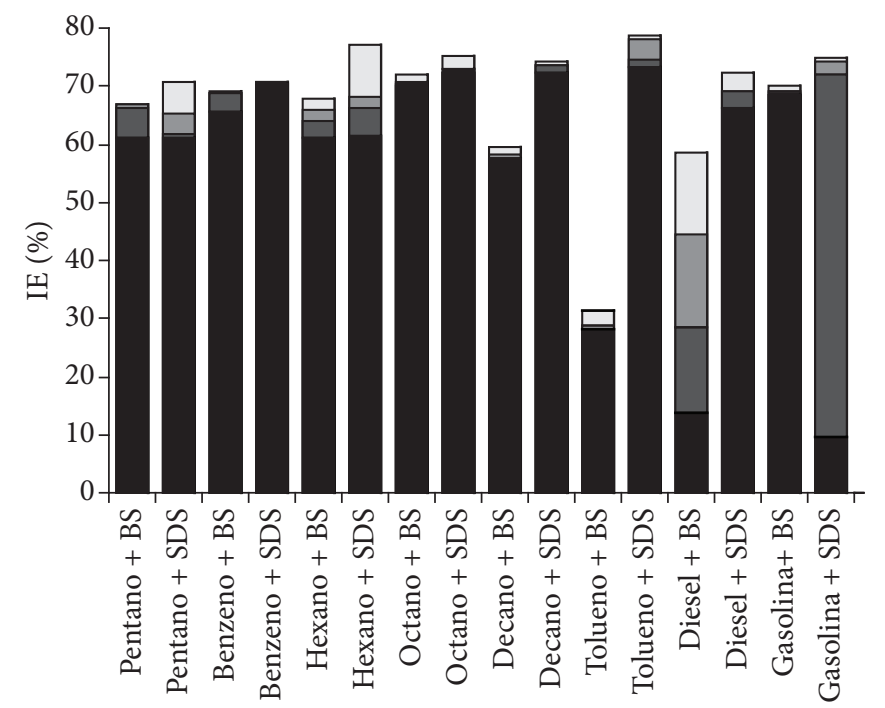

$$
\begin{array}{ll}
\text { घ(IE) } 96 \text { horas } & \square(\text { IE) } 48 \text { horas } \\
\square(\text { IE) } 72 \text { horas } & \square(\text { IE) } 24 \text { horas }
\end{array}
$$

Figura 5. Índice de Emulsificação (IE) de diferentes emulsões de hidrocarbonetos com biossurfactante de Bacillus subtilis LB5a (BS) e dodecil Sulfato de Sódio (SDS).

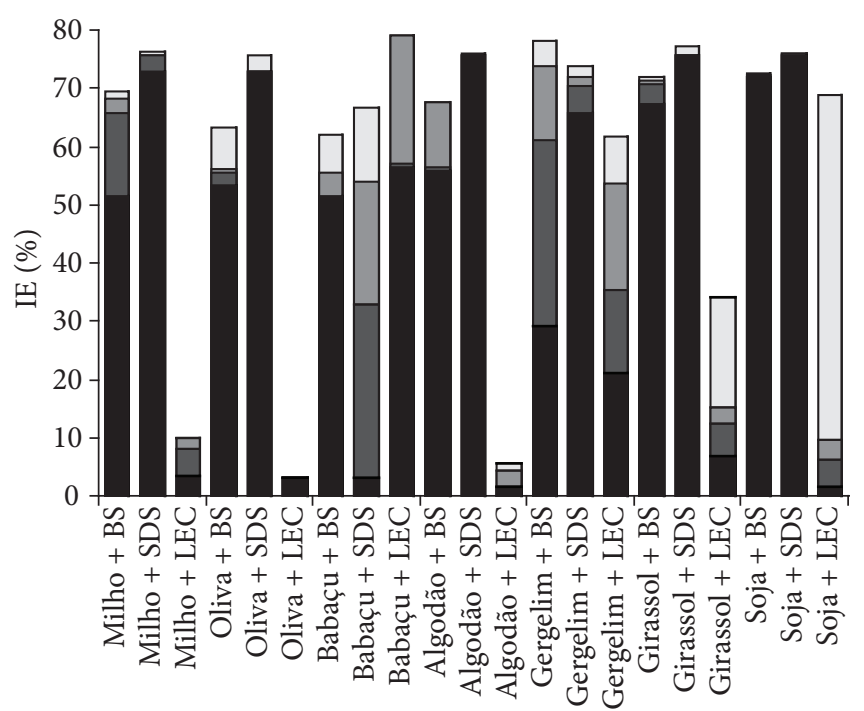

$$
\begin{array}{ll}
\square \text { (IE) } 96 \text { horas } & \square \text { (IE) } 48 \text { horas } \\
\square \text { (IE) } 72 \text { horas } & \square \text { (IE) } 24 \text { horas }
\end{array}
$$

Figura 6. Índice de Emulsificação (IE) em diferentes óleos vegetais do biossurfactante de Bacillus subtilis LB5a, do dodecil Sulfato de Sódio (SDS) e da lecitina de soja. 
Tabela 1. Composição de ácidos graxos dos óleos utilizados no experimento (ANVISA, 1999).

\begin{tabular}{|c|c|c|c|c|c|c|c|c|}
\hline & & Milho & Oliva & Babaçu & Algodão & Gergelim & Girassol & Soja \\
\hline C 8:0 & caprílico & - & - & $2,6-7,3$ & - & - & - & - \\
\hline C 10:0 & cáprico & - & - & $1,2-7,6$ & - & - & - & - \\
\hline C 12:0 & láurico & - & - & $40,0-55,0$ & - & - & - & - \\
\hline $\mathrm{C}<14$ & - & $<0,3$ & - & - & $<0,1$ & $<0,1$ & $<0,4$ & $<0,1$ \\
\hline C 14:0 & mirístico & $<0,1$ & $<0,05$ & $11,0-27,0$ & $0,4-2,0$ & $<0,5$ & $<0,5$ & $<0,5$ \\
\hline C $16: 0$ & palmítico & $9,0-14,0$ & $7,5-20,0$ & $5,2-11,0$ & $17,0-31,0$ & $7,0-12,0$ & $3,0-10,0$ & $7,0-14,0$ \\
\hline C $16: 1$ & palmitoléico & $<0,5$ & $0,3-3,5$ & $1,8-7,4$ & $0,5-2,0$ & $<0,5$ & $<1,0$ & $<0,5$ \\
\hline C $17: 0$ & margárico & - & $<0,3$ & - & - & - & - & - \\
\hline C $17: 1$ & heptadecenóico & - & $<0,6$ & - & - & - & - & - \\
\hline C 18:0 & esteárico & $0,5-4,0$ & $0,5-5,0$ & $9,0-20,0$ & $1,0-4,0$ & $3,5-6,0$ & $1,0-10,0$ & $1,4-5,5$ \\
\hline C $18: 1$ & oléico & $24,0-42,0$ & $55,0-83,0$ & $1,4-6,6$ & $13,0-44,0$ & $35,0-50,0$ & $14,0-35,0$ & $19,0-30,0$ \\
\hline C $18: 2$ & linoléico & $34,0-62,0$ & $3,5-21,0$ & - & $33,0-59,0$ & $35,0-50,0$ & $55,0-75,0$ & $44,0-62,0$ \\
\hline C $18: 3$ & linolênico & $<2,0$ & $<0,9$ & - & $0,1-2,1$ & $<1,0$ & $<0,3$ & $4,0-11,0$ \\
\hline C 20:0 & araquídico & $<1,0$ & $<0,6$ & - & $<0,7$ & $<1,0$ & $<1,5$ & $<1,0$ \\
\hline C $20: 1$ & eicosenóico & $<0,5$ & $<0,4$ & - & $<0,5$ & $<0,5$ & $<0,5$ & $<1,0$ \\
\hline C 22:0 & behênico & $<0,5$ & $<0,2$ & - & $<0,5$ & $<0,5$ & $<1,0$ & $<0,5$ \\
\hline C $22: 1$ & erúcico & - & - & - & $<0,5$ & - & $<0,5$ & - \\
\hline C 24:0 & lignocérico & $<0,5$ & $<0,2$ & - & $<0,5$ & - & $<0,5$ & - \\
\hline C $24: 1$ & tetracosenóico & - & - & - & - & - & $<0,5$ & - \\
\hline
\end{tabular}

\section{Conclusões}

Os resultados apresentados mostraram que o biossurfactante foi bastante efetivo na emulsificação de hidrocarbonetos e óleos vegetais, mesmo quando comparado ao SDS, além de manter sua estabilidade frente à condições extremas de temperatura, $\mathrm{pH}$ e salinidade. Esse resultado é bastante animador em relação à possibilidade de aplicações do biossurfactante analisado em diversos setores industriais. Esta possibilidade torna-se mais promissora com a constatação de que, não obstante o grau de pureza de o surfactante sintético ser maior que o grau de pureza do biossurfactante empregado no experimento, este se mostrou bastante efetivo.

\section{Agradecimentos}

Ao Conselho Nacional de Desenvolvimento Científico e Tecnológico - CNPq, que apoiou esta pesquisa.

\section{Referências bibliográficas}

ABU-RUWAIDA, A. S. et al. Isolation of biosurfactant-producing bacteria product characterization, and deviation. Acta Biotechnologica, v. 11, n. 4, p. 315-324, 1991.

ANVISA - AGÊNCIA NACIONAL DE VIGILÂNCIA SANITÁRIA. Resolução RDC n. 482, de 23 de setembro de 1999 revogada pela Resolução RDC n. 270, de 22 de setembro de 2005. Diário Oficial da República Federativa do Brasil, Brasília, DF, 13 de outubro de 1999, Seção 1, n. 196-E, p. 82-87.

BANAT, I. M. Les biosurfactants, plus que jamais sollicités. Biofutur, n. 198, p. 44-47, 2000.

BANAT, I. M.; MAKKAR, R. S.; CAMEOTRA, S. S. Potential commercial applications of microbial surfactants. Applied Microbiology and Biotechnology, v. 53, n. 5, p. 495-508, 2000.

BARROS, F. F. C. et al. Surfactina: propriedades químicas, tecnológicas e funcionais para aplicações em alimentos. Química Nova, v. 30, n. 2, p. 409-412, 2007.
BARROS, F. F. C. Estudo das variáveis de processo e ampliação de escala na produção de biossurfactante por Bacillus subtilis em manipueira. Campinas, 2007. 106 p. Dissertação - (Mestrado em Ciência de Alimentos), Faculdade de Engenharia de Alimentos, Universidade Estadual de Campinas - UNICAMP.

BARROS, F. F. C.; PONEZI, A. N.; PASTORE, G. M. Production of biosurfactant by Bacillus subtilis LB5a on a pilot scale using cassava wastewater as substrate. Journal of Industrial Microbiology and Biotechnology, v. 35, n. 9, 1071-1078, 2008.

BOGNOLO, G. Biosurfactants as emulsifying agents for hydrocarbons. Colloids and Surfaces A: Physicochemical and Engineering Aspects, v. 152, n. 1, p. 41-52, 1999.

CAMEOTRA S. S.; MAKKAR, R. S. Recent applications of biosurfactants as biological and immunological molecules. Current Opinion in Microbiology, v. 7, n. 3, p. 262-266, 2004.

Synthesis of biosurfactants in extreme conditions. Applied Microbiology and Biotechnology, v. 50, n. 5, p. 520-529, 1998.

COOPER, D. G.; GOLDENBERG, B. G. Surface-active agents from two Bacillus species. Applied and Environmental Microbiology, v. 53, n. 2, p. 224-229, 1987.

COOPER, D. G. et al. Enhanced production of surfactin from Bacillus subtilis by continuous product removal and metal cation additions. Applied and Environmental Microbiology, v. 42, n. 3, p. 408-412, 1981.

COSTA, G. A. N. Produção biotecnológica de surfactante de Bacillus subtilis em resíduo agroindustrial, caracterização e aplicações. Campinas, 2005. 87 p. Dissertação - (Mestrado em Ciência de Alimentos), Faculdade de Engenharia de Alimentos, Universidade Estadual de Campinas - UNICAMP.

DAVIS, D. A.; LYNCH, H. C.; VARLEY, J. The application of foaming for the recovery of surfactin from B. subtilis ATCC 21332 cultures. Enzyme and Microbial Technology, v. 28, n. 4-5, p. 346-354, 2001.

DELEU, M. et al. Interfacial and emulsifying properties of lipopeptides from Bacillus subtilis. Colloids and Surfaces A: Physicochemical and Engineering Aspects, v. 152, n. 1-2, p. 3-10, 1999. 
DESAI, J. D.; BANAT, I. M. Microbial production of surfactants and their commercial potential. Microbiology and Molecular Biology Reviews, v. 61, n. 1, p. 47-64, 1997.

DESAI, J. D.; DESAI, A. J. Production of biosurfactants. In: KOSARIC, N. (Ed.) Biosurfactants: production, properties, applications. New York: CRC Press, 1993. cap 1, p. 19-98.

HOLMBERG, K. Natural surfactants. Current Opinion in Colloid \& Interface Science, v. 6, n. 2, p. 148-159, 2001.

KIM, H. et al. Production and properties of a lipopeptide biosurfactant from Bacillus subtilis C9. Journal of Fermentation Bioengineering, v. 84, n. 1, p. 41-46, 1997.

KOSARIC, N. Biosurfactants in industry. Pure and Applied Chemistry, v. 64, n. 11, p. 1731-1737, 1992.

LANG, S. Biological amphiphiles (microbial biosurfactants). Current Opinion in Colloid \& Interface Science, v. 7, n 1-2, p. 12-20, 2002.

MAIER, R. M. Biosurfactants: evolution and diversity in bacteria. In: BENNETT, J. W.; LASKIN, A. I.; GADD, G. M. (Eds.). Advances Applied Microbiology - v. 52. USA: Academic Press, 2003. Cap. 4, p. 101-121.

MAKKAR, R. S.; CAMEOTRA, S. S. Biosurfactant production by a thermophilic Bacillus subtilis strain. Journal of Industrial Microbiology and Biotechnology, v. 18, n. 1, p. 37-42, 1997.

Structural characterization of a biosurfactant produced by Bacillus subtilis at $45^{\circ} \mathrm{C}$. Journal of Surfactants and Detergents, v. 2, n. 3, p. 367-372, 1999.
MULLIGAN, C. N. Environmental applications for biosurfactants. Environmental Pollution, v. 133, n. 2, p. 183-198, 2005.

NITSCHKE, M.; FERRAZ, C.; PASTORE, G. M. Selection of microrganisms for biosurfactante production using agroindustrial wastes. Braz. J. Microbiol. v. 35, 81-85, 2004.

NITSCHKE, M. Produção e caracterização de biossurfatante de Bacillus subtilis utilizando manipueira como substrato. Campinas, 2004. 88 p. Tese - (Doutorado em Ciência de Alimentos), Faculdade de Engenharia de Alimentos, Universidade Estadual de Campinas.

NITSCHKE, M. et al. Structural characterization and biological properties of a lipopeptide surfactant produced by Bacillus subtilis on cassava wastewater medium. Food Science and Biotechnology, v. 13, n. 5, p. 591-596, 2004.

NITSCHKE, M.; PASTORE, G. M. Production and properties of a surfactant obtained from Bacillus subtilis grown on cassava wastewater. Bioresource Technology, v. 97, n. 2, p. 336-341, 2006.

PEYPOUX, F.; BONMATIN, J. M.; WALLACH, J. Recent trends in biochemistry of surfactin. Applied Microbiology and Biotechnology, v. 51, n. 5, p. 553-563, 1999.

SHEPPARD, J. D.; MULLIGAN, C. N. The production of surfactin by Bacillus subtilis grown on peat hydrolysate. Applied Microbiology and Biotechnology, v. 27, n. 2, p. 110-116, 1987. 